\title{
Communication and internet policy: a critical rights-based history and future
}

\section{Aphra Kerr}

Department of Sociology, Maynooth University, Ireland, aphra.kerr@mu.ie

\section{Francesca Musiani}

Center for Internet and Society (CIS), National Centre for Scientific Research (CNRS), Paris, France, francesca.musiani@cnrs.fr

\section{Julia Pohle}

Berlin Social Science Center (WZB), Germany, julia.pohle@wzb.eu

Published on 31 Mar 2019 | DOI: 10.14763/2019.1.1395

\begin{abstract}
This special issue of Internet Policy Review brings together a hand-picked selection of articles presented in the Communication Policy and Technology (CPT) section at the annual conference of the International Association for Media and Communication Research (IAMCR) in Eugene, Oregon (USA), 2018. With different theoretical perspectives, methodologies, and geographical scope, the five papers in this issue address how ideal-type rights and values are translated into highly variable rules, regulations, policies and practices in different countries and regions around the world. Drawing from their respective case studies, the papers examine a number of consequences of this gap for internet users, as citizens and consumers. Building on these papers, the editorial discusses some recent evolutions of the internet policy field, and introduces the critical and 'engaged scholarship' approach that IAMCR and its CPT section have displayed over the years in their analyses of communication and internet policy.
\end{abstract}

Keywords: IAMCR, User rights, State policy, Communication rights, UNESCO

\section{Article information}

Received: 05 Mar 2019 Reviewed: 12 Mar 2019 Published: 31 Mar 2019

Licence: Creative Commons Attribution 3.0 Germany

Funding: IAMCR Sections and Working Group Fund

Competing interests: The author has declared that no competing interests exist that have influenced the text.

URL:

http://policyreview.info/articles/analysis/communication-and-internet-policy-critical-rights-based-hist ory-and-future

Citation: Kerr, A. \& Musiani, F. \& Pohle, J. (2019). Communication and internet policy: a critical rightsbased history and future. Internet Policy Review, 8(1). DOI: 10.14763/2019.1.1395 


\title{
PAPERS IN THIS SPECIAL ISSUE
}

Communication and internet policy: a critical rights-based history and future Aphra Kerr, Francesca Musiani \& Julia Pohle

Data and digital rights: recent Australian developments

Gerard Goggin, Ariadne Vromen, Kimberlee Weatherall, Fiona Martin, \& Lucy Sunman

Operationalising communication rights: the case of a "digital welfare state" Marko Ala-Fossi, Anette Alén-Savikko, Jockum Hilden, Minna Aslama Horowitz, Johanna Jääsaari, Kari Karppinen, Katja Lehtisaari, \& Hannu Nieminen

Counter-terrorism in Ethiopia: manufacturing insecurity, monopolizing speech Téwodros W. Workneh

Empire and the megamachine

Stephanie Hill

Beyond 'zero sum': the case for context in regulating zero rating in the global South

Guy Thurston Hoskins

\section{COMMUNICATION AND INTERNET POLICY: A CRITICAL RIGHTS-BASED HISTORY AND FUTURE}

March 2019 was the 3oth anniversary of the World Wide Web (WWW). Tim Berners-Lee, inventor of the WWW, called this year "a moment to celebrate how far we've come, but also an opportunity to reflect on how far we have yet to go". He argued that the future development of the internet would require governments, the private sector and internet users to share responsibility:

\begin{abstract}
Governments must translate laws and regulations for the digital age. They must ensure markets remain competitive, innovative and open. And they have a responsibility to protect people's rights and freedoms online. (...) Companies must do more to ensure their pursuit of short-term profit is not at the expense of human rights, democracy, scientific fact or public safety. Platforms and products must be designed with privacy, diversity and security in mind. (...) And most important of all, citizens must hold companies and governments accountable for the commitments they make, and demand that both respect the web as a global community with citizens at its heart.(Berners-Lee, 2019)
\end{abstract}

With this call, Berners-Lee - someone whose work has significantly contributed to making the internet a communication and information space accessible to many - publicly acknowledged the importance of policy and regulation for the future development of the internet. While internet exceptionalists like John Perry Barlow declared the independence of cyberspace from governments' control and intervention 23 years ago, a number of scholars have noted that the 
internet today is already the product of a myriad of state (democratic and authoritarian), corporate, civil society and user choices (Mansell, 2012). Today it is commonly accepted by scholars and users that internet regulation takes place in different forms and at different levels. It is also a common concern that policy and regulation - if motivated by the wrong intentions or poorly implemented - can cause fundamental harm to the global network, its technical infrastructure, its business environment and, most importantly, its users.

Many still insist that internet policies should primarily be made and implemented by technical experts, businesses or, ideally, a global multistakeholder community, and warn of the detrimental effects that the self-interests of nation states can have on the global network (Mueller, 2019). Indeed to a certain extent many areas of internet policy have been 'privatised', in the sense that private companies are playing a significant role (Curran, Fenton \& Freedman, 2012). Yet, in many democratic countries around the world, the public is increasingly looking to their national governments and regional bodies, like the European Commission, for regulatory solutions to internet-related problems, such as data protection, misinformation, illegal content, freedom of speech, net neutrality and other. Even Mark Zuckerberg, founder and chief executive of Facebook, recently called on lawmakers and regulators to strive for stronger regulation of the global internet (Zuckerberg, 2019). Whatever the motivation for such a demand, Zuckerberg's reasoning is similar to Berners-Lee's: Only by carefully (re)shaping the rules of the internet, will it be possible to protect the rights of users and preserve digital networks as a means for personal communication, public debate and the exchange of information.

Despite these calls for more and better internet policy and regulation, and the increasing spread and importance of the internet as a global communication infrastructure and platform for information services, internet policy research is still a niche topic within media and communication research. In general, social sciences and the humanities have been slow in taking up internet policy as a research field (Brosda, 2015; Dutton, 2018), with the result that the community of internet policy scholars continues to be rather small, internationally scattered, multi-disciplinary and diverse in its conceptual and methodological approaches. At the same time it is important at this juncture that the development of the next generation of internet policies and instruments is informed by scholars with expertise in developing, implementing and evaluating communication policy in the public interest, and is informed by existing laws, policies and organisations that work to protect individual and collective rights.

This special issue was formulated by the chairs of the Communication Policy and Technology (CPT) section of the International Association for Media and Communication Research (IAMCR) in discussion with the managing editor of Internet Policy Review. It aims to specifically cross some of the international and disciplinary boundaries facing internet policy researchers, and contribute to the development of internet policies that operate in the public interest. CPT has been a platform for researching telecommunications policy and infrastructure since 1974 when the section was formed by Prof. Dallas Smythe from Simon Fraser University, in Canada. By 1990 "policy" was explicitly added to the section name under the leadership of Prof. Robin Mansell, now at the London School of Economics and Political Science (LSE) in the UK. By the mid-1990s the internet had become an important consideration for members' working on communication policy, regulation and users. In the last few years it has dominated. The section encourages both theoretically robust and empirically informed research on the role that communication policy plays in relation to balancing digital service innovation with human rights and social justice. It also encourages critical and actively engaged research and researchers. 
This special issue is an important opportunity for CPT members to bring their work into conversation with the Internet Policy Review readership. While CPT members have been actively involved in studying global internet governance and policy initiatives, they also provide significant analysis of internet policies at regional and national levels, including evaluating how policies work in practice in different contexts. This issue brings together studies of internet policy and its impacts on citizens and consumers in Europe, Australia, the Americas, and Africa. While Internet Policy Review has a focus on inter and pan European contexts, our contributors make critical connections from their work to the European context where appropriate. In this introduction we provide a brief overview of recent trends and key conceptual frameworks used in internet policy research. We then provide a more detailed overview of the papers in our special issue and in particular the normative and practical challenges of assessing the impact of internet policy and governance instruments on individual and collective rights.

\section{INTERNET POLICY RESEARCH: FRAMEWORKS, ACTORS AND EMERGING CONCERNS}

While internet policy research and researchers come from multiple disciplines, and apply a range of theories and methods, they share a commitment to understanding the practice of governing the internet as a global and national infrastructure; the impact of public and private regulation on internet-based economies, communities and cultures; and the rights, responsibilities, norms and principles invoked by users and non-users. While some internet policy researchers evaluate policies developed by state actors, private companies and the institutions involved in formal political decision-making processes, others investigate alternative forms of commons based governance as well as activist and civil society initiatives. Still others are concerned with the problem definitions, discourses, laws, principles and imaginaries that proceed and inform policy decisions, policy debates and policy-making.

Internet policy research has applied a range of analytical and conceptual frameworks from various disciplines and research traditions over the past two decades. In order to assess the roles of actors in internet policy-making, communication scholars have used theories, concepts and methodological tools from political economy, social movement studies, network analysis, actornetwork theory, domestication theory, field theory, regime theory and also more classic approaches of policy analysis, such as the advocacy coalition framework (e.g., Mathiason, 2008; Milan, 2015; Pavan, 2012; Pohle, Hösl, \& Kniep, 2016). For the analysis of discourses, interests and strategies in internet policy related debates, researchers have also deployed "post-positivist" approaches such as discourse network analysis, interpretive policy analysis and online social network analysis (e.g., Epstein, Nisbet, \& Gillespie, 2011; O’Rourke \& Kerr, 2017; Pohle, 2018). More recently, scholars have started to focus on the role of institutional frameworks for internet policy and the interrelations of regulatory practices and institutions, building for example on neo-institutional theories such as historical, sociological institutionalism (e.g., Bannerman \& Haggart, 2015; Galperin, 2004; Puppis, 2010). In addition, approaches from the field of Science and Technology Studies (STS) have frequently been mobilised to analyse the role, in internet policy and governance, of the "mundane practices" of all those involved in providing and maintaining, hacking and undermining, developing, testing, and using the network of networks (see e.g. the Internet Policy Review dedicated issue, edited by Epstein, Katzenbach \& Musiani, 2016).

Deploying this broad range of conceptual approaches, initially much of the internet policy- 
related research in communication and other disciplines focused on the global nature of digital networks. Scholars tried to understand the regulatory challenges caused by the transnational character of the internet and its services, by analysing the actors and institutions involved in its coordination and regulation, in particular that of its technical infrastructure. Indeed, much of the early research work was related to the historical processes leading up to the institutionalisation of the internet's coordination and policy-making mechanisms, such as the administration of the Internet Domain Name System (DNS) and its institutionalisation in the Internet Corporation for Assigned Names and Numbers (ICANN) (e.g., Christou \& Simpson, 2007; Klein, 2000) or the World Summit on the Information Society (WSIS) and its culmination in the creation of the Internet Governance Forum (e.g., Frau-Meigs, Nicey, Palmer, Pohle, \& Tupper, 2012; Raboy, Landry, \& Shtern, 2010; Padovani, 2004; Sarikakis, 2004). Another strand of research examined how the internet as a global infrastructure could constitute not only a target of governance, but also be used as an instrument of governance in and of itself, by inscribing particular models, constraints and opportunities into the internet's technical architecture (e.g., DeNardis, 2009; Braman, 2016). Finally, during this period researchers questioned the uneven diffusion and access to the internet across regions and countries. Internet policy research succeeded in moving the debate beyond a focus on 'access' to technology to thinking about the the skills, resources and capabilities required to use the internet and the unequal user patterns that were emerging. Scholars contributed, and continue to explore, how the internet policies and technologies are implicated in patterns of inclusion and exclusion in contemporary societies, often in highly gendered terms (e.g., Padovani \& Shade, 2016; Stevenson, 2009).

More recently, in light of the increasingly complex policy frameworks regarding internet-related issues at the national level, the regulatory attempts by national or regional authorities have come to the fore amongst internet policy scholars (e.g., Collins, 2006; Löblich \& Karppinen 2014; Pohle \& Van Audenhove, 2017; see also the Internet Policy Review issue on Australian internet policy, edited by Daly \& Thomas, 2017). The majority of the empirical analyses in the field of media and communication research takes the form of case studies on particular policy issues, such as data protection and privacy, copyright, security, digital literacy, net neutrality, content regulation and increasingly also data regulation (e.g., Kruschinski \& Haller, 2017; Meyer, 2012; Mukerjee, 2016; Pierson, 2012; Powell \& Cooper, 2011; Van Audenhove, Vanwynsberghe, \& Mariën, 2018). Scholars also focussed on particular groups of actors involved in national internet policy-making, for instance activists, internet intermediaries or political parties (e.g. Breindl \& Briatte, 2013; DeNardis \& Hackl, 2015; Löblich \& Wendelin, 2012; Macq \& Jacquet, 2018). Others analysed the growing number of initiatives regarding national charters for internet rights such as the comprehensive Marco Civil framework in Brazil or similar initiatives in Europe (e.g., Cristofoletti, 2015; Gill, Redeker, \& Gasser, 2015; Padovani \& Santaniello, 2018). Very recently, the trend towards a stronger securitisation and surveillance of the online space led scholars to analyse regulatory competences for cyber security and related discourses in various countries (e.g., Hintz \& Dencik, 2016; Maréchal, 2017; Tréguer, 2017, Zeng, Stevens, \& Chen, 2017).

The internet today is a taken for granted aspect of everyday life for many people. Despite its varying quality many human activities take place on and via the internet (Bortzmeyer, 2019). This has prompted explicit discussions of the relationship between rights, values and the internet among technology practitioners, researchers and policymakers alike. Some of these issues are widely discussed, such as those related to how particular services, such as Facebook, is fighting misinformation; others are far less visible and receive much less public scrutiny, including how rights and values relate to protocols and infrastructure. The relationship between 
human rights and internet protocols is under scrutiny in a number of political and technical arenas (e.g. the Internet Research Task Force and its Human Rights Protocol Considerations research group). The relationship between emerging artificial intelligence technologies, such as machine learning, and ethics, broadly defined, is also a key policy issue at the European level, and these technologies are increasingly embedded in many of the tools developed and used by major corporations to govern user behaviour online. In 2019 the European High Level Expert Group on Artificial Intelligence (AI), established by the European Commission, released a set of Ethics Guidelines for Trustworthy AI to encourage technology companies to consider how their AI tools might impinge upon fundamental rights. Key issues include human autonomy, fairness, accountability, privacy, discrimination, diversity and fairness. This, and similar ethics initiatives, were prompted by the realisation that the design and training of algorithmic and artificial intelligence tools may introduce highly discriminatory practices which are hard to evaluate, trace and regulate after the fact (e.g., Dencik, Hintz, \& Carey, 2017; Eubanks, 2018). For some internet policy scholars a reliance on ethics alone is not sufficient, and more robust frameworks and legislation may be required. For others, ethics can be a useful mode of critique and counterbalance to the securitisation and platform capitalism discussions (e.g. Lyon, 2014). Yet, emerging guidelines tend to focus on ethics at the individual level rather then the collective or public interest values and rights, and fails to differentiate between ethics in different contexts. The policy issues may become even more complicated as AI becomes embedded in the 'Internet of Things' and our devices fade into the background of our everyday environments (e.g. Kitchin \& Dodge, 2011).

While the contexts are changing the fact that new technologies pose challenges to fundamental rights is not new. The extent to which, and how, technical artefacts are imbued with political issues, in a broad sense, is a much-debated issue in the history of technology. When it comes to the internet, the issue has perhaps been best summarised by Lawrence Lessig's "code is law" (1999) and its numerous offspring. Among them, Laura DeNardis' work (2009) has arguably been a pioneer in examining, with concepts and methods derived from STS, how protocols are political. Indeed, despite being difficult to grasp because they are intangible and often invisible to internet users, protocols have political value as they control global flows of information, influence economic competitiveness of nations and their ability to compete fairly, and often make decisions "by proxy" that influence online civil liberties and a number of individual rights, including, for example, the access to knowledge (DeNardis, 2009, p. 6).

Over the past two decades, the work of historians, philosophers and social scientists has shown that values have always entered the design of technological infrastructure; internet engineers have been no exception, asking themselves questions not only about technical optimisation but also on what it meant to build protocols that fostered individual privacy, accessibility for persons with disabilities, and other public interest concerns (Russell, 2014; Nissenbaum, 2001; Braman, 2011). Recent work has also examined how infrastructures of internet governance have become politicised and made to carry out operations that bear very little resemblance to the core technological objective of the system, and how this has unintended consequences for the stability and security of the internet, as well as human rights online (Musiani, Cogburn, DeNardis, \& Levinson, 2016). Even more recent contributions have argued that there is a "human rights gap" in internet policy, inasmuch as human rights are public - given that so far only state actors can be held responsible for not respecting them - while internet architecture is mainly privately owned or privately operated despite holding an important mediating/governing function for human rights online (Zalnieriute \& Milan, 2019).

Thus emerging issues related to the interplay of the internet, rights, and values are numerous 
and the existing evidence suggests that the issues vary from country to country and region to region. Currently the spread of misinformation and disinformation online and its implications for the democratic process, and the need to balance freedom of expression, surveillance and privacy are significant policy issues. Also of increasing importance is how to achieve cultural and content diversity on increasingly centralised digital services. The solutions will require, as Berners-Lee suggested, sharing responsibilities between transnational institutions, governments, corporations and users, but the instruments and policies that will achieve an acceptable balance between communication rights and values for all these actors are far from obvious.

\section{IAMCR AND COMMUNICATION POLICY RESEARCH BEYOND CRITIQUE}

IAMCR was founded in 1958 under the aegis of UNESCO, the UN agency in charge of education, science, culture and communication. The association's objective was to provide an international forum for researchers concerned with the importance of freedom of information and communication in journalism and mass media. Since then human rights, democratic participation, diversity, gender equality and asymmetries of power have been central to its work. During its 60 years of existence, IAMCR not only kept a close link with UNESCO but also collaborated with a range of transnational policy institutions to inform and critique policy in the areas of broadcasting, journalism and telecommunications. Its members have long been collaborating with state and civil society to develop and deploy communication policies in the public interest. As such, they often were involved in international policy debates on communication rights and the role of media and quality journalism for society, including in the Global South. For instance, in the early 1980 s several IAMCR members, including its then president and vice-president, contributed background papers to the work of the MacBride Commission (Nordenstreng, 2008: 240). This group was commissioned by UNESCO to study imbalances in global communication flows and create a scientific base for a New World Information and Communication Order (NWICO). In 2003 and 2005, many IAMCR members were participants and researchers involved in the two phases of the UN's World Summit on the Information Society (WSIS) - the first global conference discussing the chances and challenges of digital connectivity for the developing world and the controversial question of how the global internet infrastructure should be governed. In 2015, IAMCR established a clearinghouse for public statements on media and communication issues and academic freedom. Some of these statements have involved internet policy, including most recently the impact of online disinformation on democratic elections.

Members of IAMCR have long argued that policy makers and regulators need to attend to the internet as a socio-technical system. Mansell (2012) for example has documented the competing social imaginaries dominating the development of the internet: a market led approach which aims to limit regulation by state and other actors and an information commons imaginary which also favours limited regulation. Despite the widespread discourse that the internet is ungovernable due to its decentralised and non hierarchical network structure, for many years, academics have uncovered a range of ways in which the infrastructure, services and content are governed from above and below in favour of particular interests. To date internet policies in many countries are dominated by state and corporate actors. What is of concern to social science theorists is the lack of transparency and responsibility in these governance arrangements and processes, and the lack of fora where alternative approaches in the public 
interest can be developed (Helberger, Pierson, \& Poell, 2018; Kerr, De Paoli, \& Keatinge, 2014).

Of course some transnational internet policy initiatives have emerged in the last two decades. After their involvement in WSIS, IAMCR members were attentive to the rise of the Internet Governance Forum (IGF), a global venue for multi-stakeholder policy discussions on internetrelated issues that the United Nations created as one of the WSIS outcomes in 2006; after being hosted by UNESCO in Paris in 2018, the fourteenth meeting of this forum takes place in Berlin in 2019. In 2015, IAMCR members also contributed to the 10-year review of the World Summit on the Information Society (WSIS+10) and the renewed discussions on communication rights, imbalances and global challenges in the digital age. Since 2016 IAMCR hosted a series of special sessions on UNESCO's recent initiative to develop the concept of 'Internet Universality'. This concept highlights the importance for the future development of the internet to be based on the principles of human rights, openness, accessibility and multi-stakeholder participation; it also links internet development to sustainable development and to distributing more widely the benefits of the knowledge society. In 2018 UNESCO released its Internet Universality Indicators which were developed based on the inputs of researchers around the world, including IAMCR members, and provide an instrument for stakeholders to conduct national assessments of internet development. It remains to be seen what impact such initiatives have on policies and practice.

The Communication Policy \& Technology (CPT) section is the venue within IAMCR where empirical and theoretical policy research on communication and technology-related aspects is featured most prominently. It has been chaired by a number of international academics from Europe, the Americas and Asia, some of whom have also worked as policymakers, or closely with communication policymakers (e.g., Dunn, 2010; Melody, 1996; 1999; Samarajiva, 1994). Initially dominated by work on satellite, telecommunications and broadcast systems, since the 1990 s members have been actively concerned with how the internet impacts on the rights of citizens and consumers globally. This focus on 'policy in practice' means that the section encourages papers that bridge theory and practice, that critically engage with the impact of internet policies and, sometimes, provides recommendations for political action and policymakers (e.g., Mansell, 2011; Frau-Meigs, 2012). It encourages work that evaluates the roles of different institutions and the interaction between top down and bottom up perspectives (e.g. Michalis, 2007). Members evaluate the effectiveness of multi-stakeholder practices and the reality of activism by civil society (e.g., Cammaerts \& Carpentier, 2005; Hintz \& Milan, 2009). The section also organises joint sessions with other sections including the law section and the Global Media Policy Working Group. Its members collaborate and are involved in IAMCR's most visible publication projects, such as the Handbook of Global Media and Communication Policy (Mansell \& Raboy, 2011) which included chapters on the emerging conceptual and methodological challenges posed by the internet for media and communication researchers.

\section{SPECIAL ISSUE: INTERNET POLICY AND PRACTICE AROUND THE WORLD}

This special issue presents papers from the CPT section of the annual IAMCR conference which took place in Eugene, Oregon, USA in 2018. The conference theme was 'Reimagining Sustainability: Communication and Media Research in a Changing World', a theme which resonates with the UN Sustainable Development Goals. We invited all internet policy related papers to contribute to this special issue and after three rounds of open peer review we are 
delighted to present a sample of the excellent scholarship in the CPT section.

As IAMCR is an interdisciplinary organisation, the papers in this issue come from social, political and communication sciences. The selection includes papers by emerging scholars as well as more established academics. They are empirically grounded in different regions - from Africa, America, Australia, and Europe - and while limited in number we are certain that they contribute to our understanding of how rights and values are refracted through different economic, political and cultural perspectives, internet policies and networked forms of governance. In particular, these papers seek to identify the logics and values embedded in state, corporate and non-governmental policies and practices, and the varying impact of these policies and practices on citizens and consumers. Further, we find that civil liberties and social values often get narrowed to legal and technocratic principles or measurable values. This has varying implications for citizen agency in situations often characterised by power asymmetries and significant resource differentials.

The five papers presented in this special issue share a common preoccupation. All of them put at the core of their work the potential impact that communication technology-based networked systems and policies can have on users - in their multiple facets of consumers, citizens and policy targets - and on their rights vis-à-vis other actors and stakeholders in such systems, including private companies, civil society organisations, and of course the state in its different forms and instances. Taken together, the articles contribute to the complex portrait of internet policy today by questioning the impact of state policies on citizen rights, in particular surveillance and privacy-related ones, and the ways in which it can be measured; addressing the impact of lateral and state oversight of company policies and activities; observing the different shapes and configurations taken by networked forms of governance; and finally, examining how civil liberties, social justice and human rights perspectives can still unfold in today's increasingly centralised internet, and how best to safeguard them.

In their article, Gerard Goggin and his colleagues address the specificities of the digital rights debates in Australia, while, at the same time, situating them in a broader context of global discussions about data privacy and the means to enforce it. Taking as a case study two recent Australian policy developments, the "Digital Platforms Inquiry" and the development of a consumer data right, the article makes a case for the importance of national contexts in assessing how digital rights can be enacted. It emphasises the necessity for states to engage seriously with citizens regarding their knowledge, expectations and experience of digital rights as a crucial component of law-making.

Another article which focuses on how digital rights are defined and operationalised in a particular national context is authored by Marko Ala-Fossi and colleagues. This paper proposes a model to analyse the concept of communication rights that is based on understanding the changing role of communication in a social democracy, using Finland as a country case study. The authors pay specific attention to four core rights - access, availability, dialogicality, and privacy - and they examine how these rights are negotiated in the development of digital services at four levels: the regulatory, the public sector, the commercial, and the citizen-consumer. In the Finnish context we see an evolving and distinctive approach to privacy and the 'epistemic commons', but also a clear tension between established communication rights in this social democratic state, and emerging commercial incentives, European privacy legislation and citizen consumer online activities.

The question of the impact of state-led internet policy on digital rights is also at the heart of Téwodros Workneh's article, which focuses on the dialectic between surveillance and 
freedom of expression in Ethiopia. Situating the research in the neopatrimonial state framework, the article discusses how a counter-terrorism legal instrument, promulgated in 2009, has become a way for the Ethiopian state to stifle freedom of expression involving mediated communication, especially on digital platforms. By means of this case study, Workneh draws broader lessons on the impact of counter-terrorism laws on freedom of expression globally, and on the consequences of this phenomenon for internet policy.

The core policy role of digital platforms for civil liberties is an issue also tackled in Steph Hill's contribution. Blending political economy and media studies approaches, this paper seeks to understand how private sector-led governance can gain prominence with respect to state-led policy by examining two controversies over social media content that happened in 2017: the socalled "adpocalypse", a hiatus in several prominent companies' advertising on social media platforms due to the co-location of their online advertisements with problematic content, and the first public hearings over Russian operatives disseminating misinformation in relation to the 2016 US presidential elections. Social media companies' actions, the author warns, indicate an expanded role for marketing and advertising firms as "controllers" of media content, while, democratic representatives often take the back seat.

Finally, the paper by Guy Hoskins, recipient of the inaugural CPT and Internet Policy Review award, examines a core and controversial sub-topic of the network neutrality issue, zero-rating the practice of providing internet access for free under specific conditions, such as restricted access to certain websites. Mixing political economy and ICT for development approaches, the author proposes to draw together the issues of network neutrality, digital divide and digital inclusion, and their relationship to zero rating, for a better understanding of the phenomenon. A comparative analysis of four wireless markets in the Global South - Brazil, Colombia, Mexico and South Africa - allows the author to paint a detailed portrait of zero rating as the product of multiple, interweaved factors that greatly nuance the "access vs. neutrality" equation that has, so far, summed up the phenomenon.

With this special issue of the Internet Policy Review, we aim to set the frame for illustrating one of the core issues that internet policy researchers face today: untangling the normative and practical challenges of assessing the impact of internet policy on individual and collective rights. Taken together, the articles in this special issue show that internet policy is being studied through an increasingly strong hybridisation of disciplines and issues that, until recently, have been addressed by relatively separate research traditions. In addition, they make us reflect on this hybridity. Discussions on the digital divide, inclusion, and ICTs for development are closer than we might think to the nitty-gritty political economy of net neutrality, as Hoskins shows. Controversies over advertising strategies and content choice on social media, as examined by Hill, are strongly intertwined with internet governance and its privatisation, as well as 'classical' conceptualisations of Empire from Innis. While scholarship on the issue of surveillance most prominently associates it with privacy and data protection, Workneh demonstrates its close ties with freedom of expression, and proposes, with the neopatrimonial state framework, an original way to address it. Finally, Goggin et al. and Ala-Fossi et al. clearly demonstrate the extent to which the 'global' internet as a worldwide system needs, now more than ever, to be grounded in analyses of national studies of internet policy creation and application, each with their unique mix of state-led intervention, private sector strategies, and the role of internet users as citizens and consumers.

Weaving an increasingly tangled nexus of disciplines, issues and objects, internet policy research has evolved over time, responding to both technological evolutions, changes in power balances 
and the birth and development of new 'networked' socio-political issues. Academic organisations such as IAMCR have evolved in response to these changes. It has especially been the case for the CPT section, as the three elements composing its title -- communication, policy and technology -- moved from covering satellite and broadcast technology to examining a wide range of networking and connected technical artifacts, which nowadays extend to the most recent internet developments, including artificial intelligence, algorithms, and the internet of things. What has remained strong however is the critically engaged research and the scholars who contribute to the organisation, and who bring normative and diverse values to bear on the evolving logics of internet policies. As we plan the next IAMCR conference in Madrid, the papers in this special issue are a stimulating guide to the importance of this work.

\section{ACKNOWLEDGMENT}

We would like to acknowledge the support of the IAMCR Sections and Working Group Fund which made this open access publishing collaboration possible. Aphra would like to thank the Institute for Advanced Studies in Humanities and the School of Social and Political Science at the University of Edinburgh who are hosting her from February to May 2019. All papers went through open peer review and we want to thank the generous efforts of all our reviewers. This special issue would not have been possible without the support, input and patience of the Internet Policy Review's managing editor, Frédéric Dubois. 


\section{REFERENCES}

Bannerman, S., \& Haggart, B. (2015). Historical Institutionalism in Communication Studies. Communication Theory, 25(1), 1-22. doi:10.1111/comt.12051

Berners-Lee, T. (2019, March 12). 30 years on, what's next \#ForTheWeb?. World Wide Web Foundation. Retrieved from: https://webfoundation.org/2019/o3/web-birthday-30/.

Bortzmeyer, S. (2019). Cyberstructure. L'Internet, un espace politique [Cyberstructure. The internet, a political space]. Caen: C \& F Éditions.

Braman, S. (2011). Internet policy. In M. Consalvo \& C. Ess (Eds.), Handbook of Internet Studies (pp. 137-167), Oxford: Wiley-Blackwell. doi:10.1002/9781444314861.ch7

Braman, S. (2016). Instability and internet design. Internet Policy Review, 5(3).

doi:10.14763/2016.3.429

Breindl, Y., \& Briatte, F. (2013). Digital Protest Skills and Online Activism Against Copyright Reform in France and the European Union. Policy \& Internet, 5(1), 27-55. doi:10.1002/poi3.21

Brosda, C. (2015). Orientierung in der digitalen Unübersichtlichkeit. Zur medienpolitischen Relevanz der Kommunikationswissenschaft. In M. Emmer \& C. Strippel (Eds.),

Kommunikationspolitik für die digitale Gesellschaft (pp. 25-40). Berlin: Freie Universität Berlin, Institut für Publizistik- und Kommunikationswissenschaft. doi:10.17174/dcr.v1.3

Cammaerts, B. \& Carpentier, N. (2005). The Unbearable Lightness of Full Participation in a Global Context: WSIS and Civil Society participation. In J. Servaes \& N. Carpentier (Eds.), Towards a Sustainable Information Society: Beyond WSIS (pp. 17-49). Bristol: Intellect Books

Christofoletti, R. (2015). Privacidade e Regulamentação do Marco Civil da Internet: registros e preocupações [Privacy and Regulation of the Civil Framework of the Internet: records and concerns]. Revista ECO-Pós, 18(3), 213-229. doi: 10.29146/eco-pos.v18i3.2150

Christou, G., \& Simpson, S. (2007). Gaining a Stake in Global Internet Governance: The EU, ICANN and Strategic Norm Manipulation. European Journal of Communication, 22(2), 147-164. doi:10.1177/0267323107076765

Collins, R. (2006). Internet governance in the UK. Media, Culture \& Society, 28(3), 337-358. doi:10.1177\%2F0163443706061686

Curran, J., Fenton, N., \& Freedman, D. (2012). Misunderstanding the Internet. London: Routledge. doi:10.4324/9780203146484

Daly, A., \& Thomas, J. (2017). Australian internet policy. Internet Policy Review, 6(1). doi:10.14763/2017.1.457

DeNardis, L. (2009). Protocol politics: The globalization of Internet governance. Cambridge, MA: The MIT Press.

DeNardis, L., \& Hackl, A. M. (2015). Internet governance by social media platforms. Telecommunications Policy, 39(9), 761-770. doi:10.1016/j.telpol.2015.04.003

Dencik, L., Hintz, A., \& Carey, Z. (2017). Prediction, pre-emption and limits to dissent: Social 
media and big data uses for policing protests in the United Kingdom. New Media \& Society, 2O(4), 1433-1450. doi:10.1177/1461444817697722

Dunn, H. S. (2010). Information Literacy and the Digital Divide: Challenging e-Exclusion in the Global South. In E. Ferro, Y. K. Dwivedi, J. R. Gil-Garcia, \& M. D. Williams (Eds.), Handbook of Research on Overcoming Digital Divides: Constructing an Equitable and Competitive Information Society (Vol. 1, pp. 326-344). Hershey, PA: Information Science Reference (an imprint of IGI Global). doi:10.4018/978-1-60566-699-0.cho18

Dutton, W. H. (2018). Networked publics: multi-disciplinary perspectives on big policy issues. Internet Policy Review, 7(2). doi:10.14763/2018.2.795

Epstein, D., Katzenbach, C. \& Musiani, F. (2016). Doing internet governance: practices, controversies, infrastructures, and institutions. Internet Policy Review, 5(3).

doi:10.14763/2016.3.435

Epstein, D., Nisbet, E. C., \& Gillespie, T. (2011). Who's Responsible for the Digital Divide? Public Perceptions and Policy Implications. The Information Society, 27(2), 92-104. doi:

\subsection{0/01972243.2011.548695}

Eubanks, V. (2018). Automating Inequality. How High-Tech Tools Profile, Police and Punish the Poor. New York: St Martin's Press.

Frau-Meigs, D. (2012). Transliteracy as the New Research Horizon for Media and Information Literacy. Media Studies, 3(6), 14-27.

Frau-Meigs, D., Nicey, J., Palmer, M., Pohle, J., \& Tupper, P. (Eds.) (2012). From NWICO to WSIS: 30 Years of Communication Geopolitics - Actors and Flows, Structures and Divides. Bristol: Intellect Books. doi:10.1177/0267323113476942b

Galperin, H. (2004). Beyond Interests, Ideas, and Technology: An Institutional Approach to Communication and Information Policy. The Information Society, 2O(3), 159-168. doi:

\subsection{0/01972240490456818}

Gill, L., Redeker, D., \& Gasser, U. (2015). Towards Digital Constitutionalism? Mapping Attempts to Craft an Internet Bill of Rights (Research Publication No. 2015-15). Cambridge, MA: The Berkman Center for Internet \& Society at Harvard University. Retrieved from http://nrs.harvard.edu/urn-3:HUL.InstRepos:28552582

Hintz, A., \& Dencik, L. (2016). The politics of surveillance policy: UK regulatory dynamics after Snowden. Internet Policy Review, 5(3). doi:10.14763/2016.3.424

Hintz, A., \& Milan, S. (2009). At the margins of Internet governance: grassroots tech groups and communication policy. International Journal of Media \& Cultural Politics, 5(1), 23-38. doi:10.1386/macp.5.1-2.23_1

Helberger, N., Pierson, J., \& Poell, T. (2018). Governing online platforms: From contested to cooperative responsibility. The Information Society, 34(1), 1-14.

doi:10.1080/01972243.2017.1391913

Kerr, A., De Paoli, S., \& Keatinge, M. (2014). Surveillant Assemblages of Governance in Massively Multiplayer Online Games: a comparative analysis. Surveillance and Society, 12(3), 
320-336. doi:10.24908/ss.v12i3.4953

Kitchin, R., \& Dodge; N. (2011). Code/space: Software and everyday life, Cambridge, MA: The MIT Press.

Klein, H. (2002). ICANN and Internet Governance: Leveraging Technical Coordination to Realize Global Public Policy. The Information Society, 18(3), 193-207.

https://doi.org/10.1080/01972240290074959

Kruschinski, S., \& Haller, A. (2017). Restrictions on data-driven political micro-targeting in Germany. Internet Policy Review, 6(4). doi:10.14763/2017.4.780

Lessig, L. (1999). Code: And Other Laws Of Cyberspace. New York: Basic Books.

Löblich, M., \& Karppinen, K. (2014). Guiding Principles for Internet Policy: A Comparison of Media Coverage in Four Western Countries. The Information Society, 30(1), 45-59.

https://doi.org/10.1080/01972243.2013.855688

Löblich, M., \& Wendelin, M. (2012). ICT policy activism on a national level: Ideas, resources and strategies of German civil society in governance processes. New Media \& Society, 14(6),

899-915. https://doi.org/10.1080/01972243.2013.855688

Lyon, D. (2014). Surveillance, Snowden, and Big Data: Capacities, consequences, critique. Big

Data \& Society, 1(2). https://doi.org/10.1177/2053951714541861

Macq, H. \& Jacquet, V. (2018). S'engager dans un cyberparti. Internet et militantisme au sein du parti pirate belge [To engage in a cyberparty: Internet in the Belgian Pirate Party Membership]. RESET, 7. doi:10.400o/reset.1102

Mansell, R. (2011). New visions, old practices: Policy and regulation in the Internet era. Continuum, 25, 19-32. doi:10.1080/10304312.2011.538369

Mansell, R. (2012). Imagining the Internet: Communication, Innovation, and Governance. Oxford, UK: Oxford University Press.

Mansell, R., \& Raboy, M. (Eds.). (2011). The Handbook of Global Media and Communication Policy. Chichester, West Sussex: Wiley-Blackwell. doi:10.1002/9781444395433

Maréchal, N. (2017). Networked Authoritarianism and the Geopolitics of Information: Understanding Russian Internet Policy. Media and Communication, 5(1), 29-41. doi:10.17645/mac.v5i1.808

Mathiason, J. (2008). Internet Governance $\square$ : The New Frontier of Global Institutions. London: Routledge. doi:10.4324/9780203946084

Milan, S. (2015). From social movements to cloud protesting: the evolution of collective identity. Information, Communication \& Society, 18(8), 887-90o. doi:10.1080/1369118x.2015.1043135

Melody, W. H. (1996). Towards a framework for designing information society policies. Telecommunications Policy, 20(4), 243-259. doi:10.1016/0308-5961(96)oooo7-9

Melody, W. H. (1999). Telecom reform: progress and prospects. Telecommunications Policy, 23(1), 7-34. doi:10.1016/so3o8-5961(98)ooo73-1 
Meyer, T. (2012). Graduated Response in France: The Clash of Copyright and the Internet. Journal of Information Policy, 2, 107-127. doi:10.5325/jinfopoli.2.2012.0107

Michalis, M. (2007). Governing European Communications: From unification to coordination. Lanham, MD: Lexington Books.

Mueller, M. (2019, April 2). Why we should say No to Facebook's call to "Regulate the Internet". Internet Governance Project. Retrieved from:

https://www.internetgovernance.org/2019/04/o2/why-we-should-say-no-to-facebooks-call-toregulate-the-internet/.

Mukerjee, S. (2016). Net neutrality, Facebook, and Indias battle to \#SaveTheInternet. Communication and the Public, 1(3), 356-361. doi:10.1177/2057047316665850

Musiani, F., Cogburn, D. L., DeNardis, L., \& Levinson, N. S. (Eds.) (2016). The turn to infrastructure in Internet governance. New York: Palgrave-Macmillan.

doi:10.1057/9781137483591

Nissenbaum, H. (2001). How computer systems embody values. Computer, 34(3), 119-120. doi:10.1109/2.910905

Nordenstreng, K. (2008). Institutional Networking: The Story of the International Association for Media and Communication Research (IAMCR). In D. W. Park \& J. Pooley (Eds.), The History of Media and Communication Research: Contested Memories. New York: Peter Lang. doi:10.1177/0196859909334842

O'Rourke, C., \& Kerr, A. (2017). Privacy Shields for Whom? Key Actors and Privacy Discourses on Twitter and in Newspapers. Westminster Papers in Communication and Culture, 12(3). doi:10.16997/wpcc.264

Padovani, C. (2004). The World Summit on the Information Society: Setting the Communication Agenda for the 21st Century? An Ongoing Exercise. International Communication Gazette, 66(3-4), 187-191. doi:10.1177/0016549204043604

Padovani, C., \& Shade, L. R. (2016). Introduction to the Special Issue: Gendering Global Media Policy: Critical Perspectives on "Digital Agendas". Journal of Information Policy, 6(1), 332-337. doi:10.5325/jinfopoli.6.2016.0332

Padovani, C., \& Santaniello, M. (2018). Digital constitutionalism: Fundamental rights and power limitation in the Internet eco-system. International Communication Gazette, 80(4), 295-301. doi:10.1177/1748048518757114

Pavan, E. (2012). Frames and Connections in the Governance of Global Communications: A Network Study of the Internet Governance Forum. Lanham, MD: Lexington Books.

Pierson, J. (2012). Online privacy in social media: a conceptual exploration of empowerment and vulnerability. Communications \& Strategies, 88, 99-120

Pohle, J. (2018). The Internet as a global good: UNESCO's attempt to negotiate an international framework for universal access to cyberspace. International Communication Gazette, 80(4), 354-368. doi:10.1177/1748048518757140

Pohle, J., Hösl, M., \& Kniep, R. (2016). Analysing internet policy as a field of struggle. Internet 
Policy Review, 5(3).

Pohle, J., \& van Audenhove, L. (2017). Post-Snowden Internet Policy: Between Public Outrage, Resistance and Policy Change. Media and Communication, 5(1), 1-6.

doi:10.17645/mac.v5i1.932

Powell, A., \& Cooper, A. (2011). Net neutrality discourses: comparing advocacy and regulatory arguments in the United States and the United Kingdom. The Information Society, 27(5), 311-325. doi:10.1080/01972243.2011.607034

Puppis, M. (2010). Media Governance: A New Concept for the Analysis of Media Policy and Regulation. Communication, Culture \& Critique, 3(2), 134-149. doi:10.1111/j.17539137.2010.01063.x

Raboy, M., Landry, N., \& Shtern, J. (2010). Digital Solidarities, Communication Policy and Multi-stakeholder Global Governance: The Legacy of the World Summit on the Information Society. New York: Peter Lang.

Russell, A. L. (2014). Open standards and the digital age. Cambridge: Cambridge University Press.

Samarajiva, R. (1994). Privacy in Electronic Public Space: Emerging Issues. Canadian Journal of Communication, 19(1). doi:10.22230/cjc.1994v19n1a796

Sarikakis, K. (2004). Ideology and policy: Notes on the shaping of the Internet. First Monday, 9(8). doi:10.5210/fm.v9i8.1167

Stevenson, S. (2009). Digital Divide: A Discursive Move Away from the Real Inequities. The Information Society, 25(1), 1-22. 10.1080/01972240802587539

Tréguer, F. (2017). Intelligence Reform and the Snowden Paradox $\square$ : The Case of France. Media and Communication, 5(1). doi:10.17645/mac.v5i1.821 Available at https://hal.archivesouvertes.fr/hal-01481648/

Van Audenhove, L., Vanwynsberghe, H., \& Mariën, I. (2018). Media Literacy Policy in Flanders - Belgium: From Parliamentary Discussions to Public Policy. Journal of Media Literacy Education, 10(1), 59-81. doi: 10.23860/jmle-2018-10-1-4

Zalnieriute, M., \& Milan, S. (2019). Internet Architecture and Human Rights: Beyond the Human Rights Gap. Policy \& Internet, 11(1), 6-15. doi:10.1002/poi3.200

Zeng, J., Stevens, T., \& Chen, Y. (2017). China’s Solution to Global Cyber Governance: Unpacking the Domestic Discourse of "Internet Sovereignty". Politics \& Policy, 45(3), 432-464. doi:10.1111/polp.12202

Zuckerberg, M. (2019, March 30). The Internet needs new rules. Let's start in these four areas. The Washington Post. Retrieved from: https://www.washingtonpost.com/opinions/markzuckerberg-the-internet-needs-new-rules-lets-start-in-these-fourareas/2019/03/29/9e6fo504-521a-11e9-a3f7-78b7525a8d5f_story.html 